\title{
COMMUTING AND HAPPINESS \\ What ways feel best for what kinds of people? ${ }^{1}$
}

\author{
Sascha Lancée, Martijn Burger and Ruut Veenhoven ${ }^{2} 3$
}

In: Friman, M., Ettema, D. \& Olson, E. (EDS) 'Quality of life and daily travel' Chapter 5, pp. 73-93, Springer International Publishing AG, 2018 Dordrecht Netherlands, ISBN 978-3-31976623-2

\begin{abstract}
Question: How happy we are, depends partly on how we live our life and part of our way of life is how we commute between home and work. In that context, we are faced with the question of how much time spent on commuting is optimal happiness wise and with what means of transportation we will feel best. Decisions about commuting are typically made as a side issue in job choice and there are indications that we are bad in predicting how such decisions will work out on our happiness in the long-run. For that reason, it is helpful to know how commuting has worked out on the happiness of other people and on people like you in particular.
\end{abstract}

Earlier research: Several cross-sectional studies found lower happiness among long-distance commuters and among users of public transportation. Yet these differences could be due to selection effects, such as unhappy people opting more often for distant jobs without having a car. Still another limitation is that earlier research has focused on the average effect of commuting, rather than specifying what is optimal for whom.

Method: Data of the Dutch 'Happiness Indicator' study was analyzed, in the context of which 5000 participants recorded what they had done in the previous day and how happy they had felt during these activities. This data allows comparison between how the same person feels at home and during commute, which eliminates selection effects. The number of participants is large enough to allow a split-up between different kinds of people, in particular among the many well-educated women who participated in this study.

Results: People feel typically less happy when commuting than at home, and that the negative difference is largest when commuting with public transportation and smallest when commuting by bike. It is not per se the commuting time that causes happiness loss, but

\footnotetext{
${ }^{1}$ An extended version of this paper was published in Transportation Research Part A 104C (2017) pp. 195-208, DOI: 10.1016/j.tra.2017.04.025

${ }^{2}$ Corresponding author; veenhoven@ese.eur.nl

3 Second affiliation: Opentia Research Program, North-West University, South Africa
} 
specific combinations of commuting time and commuting mode. Increasing commuting times can even lead to a gain in happiness for certain types of women, when the commute is by bike.

Split-up by different kinds of people shows considerable differences, such as an optimal commute alone or even by public transport for some highly educated women. Optimal ways of commuting for different kinds of people are presented in a summary table, from which individuals can read what will fit them best. The differences illustrate that research focusing on average effects of happiness will not help individuals in making a more informed choice.

Keywords: happiness, commuting, experience utility, informed choice, DRM.

\section{INTRODUCTION}

The last few decades show a rising interest in happiness, also known as 'life satisfaction' and 'subjective wellbeing'. This topic has been around since antiquity in Western society and has been much debated ever since. Happiness was once an object of theoretical speculation, now it is an object of empirical research in the social sciences and increasingly in economics (Layard, 2005; Frey \& Stutzer, 2002). The rise of scientific interest in happiness is part of a wider cultural change, in which 'quality of life' gains prominence relative to traditional values such as religious devotion and societal success (Veenhoven 2016)

Empirical research on happiness has shown that most people are happy, at least in contemporary developed nations (Veenhoven, 2015a). Research in modern societies has also shown that greater happiness is possible for most people and that an individual's happiness depends to a considerable degree on the choices that one makes in life (Lyubomirsky, 2008). As people typically want to live a happy life, there is a demand for information on the effects of choices on happiness. This information demand reflects in soaring sales of 'how to be happy books' and the development of the life-coaching business. Although much of this advice is based on folk-wisdom, empirical happiness research is increasingly used to support the informed pursuit of happiness (Veenhoven, 2015c).

One of the choices we make is how we travel between work and home, an important aspect of modern life, which takes up a lot of time of daily life. Even in a small country such as the Netherlands, commuting is a surprisingly time-consuming activity with an average commuting time of 34.5 minutes one way (ANWB 2015), while at the same time commuting time and distances increased considerably over the past decades (Van Wee et al., 2006; Susilo and Maat, 2007). To make a well-informed choice on this matter it is helpful to know how different aspects of commuting have affected the happiness of other people in general and of people like us in particular. 
Hence, the question addressed in this paper is 'What does optimal commuting look like to enhance happiness for whom?' To answer this question, three related sub-questions will be answered.

1. Does commuting affect happiness? If so, how much?

2. Which aspects of commuting influence happiness most and least?

3. How different are these effects across persons and situations?

\section{PREVIOUS RESEARCH}

Commuting is an important and increasing part of how workers use their time. For instance, Koslowsky et al. (1995) note that psychologists have long recognized the possible negative effects of commuting on psychological health and found that commuting is often experienced as an unpleasant experience that has delayed effects on health and family life. Amongst others, commuting leads to increased anxiety and hostility (Koslowsky et al., 1995). Since Koslowsky et al. (1995), more and more research has looked into the relationship between commuting and happiness, which in general states that commuting has a negative effect on life satisfaction, also known as subjective well-being (Pfaff, 2014; Dolan et al., 2006; Frey \& Stutzer, 2014). Moreover, Kahneman et al. (2003) found that commuting appears to be the daily activity that generates the lowest level of positive affect and a high level of negative affect. Important negative aspects of commuting are boredom and increased social isolation, which leads to unhappiness (Gatersleben \& Uzzell, 2007; Putnam, 2000).

\subsection{Topics}

Several aspects of commuting in specific add to the negative consequences of commuting while others help diminish these effects. These aspects will now be discussed.

\section{Commuting time}

Stutzer and Frey (2008) have researched the effects of commuting on subjective well-being in Germany in a study of 14 years. Their research found that people with a longer commuting time systematically indicate that they have a lower subjective well-being. In a replication study, Studer and Winkelmann (2011) found similar results. However, they also found that very satisfied people are less affected by an increasing commuting time than people who are dissatisfied with their life. Research by the Office for National Statistics (ONS) in the United Kingdom indicates that each successive minute of travel decreases the level of life satisfaction. Average levels of happiness significantly drop after 15 minutes of commuting and life satisfaction after 45 minutes of commuting. In general, the worst effects come from commuting times between 60 and 90 minutes (ONS, 2014). Van der Meer and Wielers (2013) indicate that commuting times defined as short and long have larger negative effect on happiness than moderate commuting times. Commuting time is also negatively 
associated with satisfaction with the environment, health satisfaction and satisfaction with spare time (Kahneman et al., 2003).

\section{Commuting mode}

Research on commuting mode and subjective wellbeing has generally found that cycling and walking to work contribute to higher levels of subjective wellbeing compared to motorized travel (Duarte et al., 2010; Friman et al., 2013; Olsson et al., 2013; Ettema and Smajic, 2014; Morris and Guerra, 2015; Chng et al., 2016). In particular, Ettema and Smajic (2014) found that the level of physical activity involved in walking increases mental health and enhances the mood, indicating that commuting modes involving physical activity might have a lower negative or even positive effect on happiness. On a different note, several studies have reported that commuting by car generates higher levels of subjective wellbeing than commuting by public transportation or transit (Mokhtarian and Solomon, 2001; Ettema et al., 2011; Abou-Zeid et al., 2012; Morris and Guerra, 2015; Olsson et al., 2013). As pointed out by Morris and Guerra (2015), the difference in subjective wellbeing of car and public transport commuters can be explained by factors such as prestige, self-esteem, convenience, comfort, reliability, and greater control over one's environment.

\section{Travelling alone or together}

According to Ettema et al. (2012) the strongest positive effect on satisfaction with travel is talking to others during the travel. This indicates how travelling alone or together can influence the commuters' happiness.

\section{Rush hour}

Commuting can be a major cause of stress due to its unpredictability and perceived loss of control (Roberts et al., 2011). When people do not have control over certain factors that can occur during driving, commuting is experienced as more stressful and leads people to report lower experienced well-being. Drivers generally experience a lesser feeling of control during rush hours when environmental stressors are the highest and the driver needs a higher level of concentration to focus on his task.

\section{To work or back home}

Ettema et al. (2012) examined the difference between commuting to work and from work on satisfaction with travel. It appears that commuters have different mindsets when travelling to and from work. While commuters on the way to work prepare themselves for a working day, on the way home the prospect of private time enables them to be more open to enjoying the commute. This is also shown for ICT use in public transport, which has a negative effect on well-being on the way to work when ICT use is possibly work related, whereas it has a positive effect on well-being on the way home when ICT is possibly used to coordinate private time (Ettema et al., 2012). This indicates that the experienced happiness 
when commuting may also be different to and from work. See also Olsson et al. (2013). In contrast, Koslowsky et al. (1995) found that commuting always leads to a bad temper, either when arriving at work or at home.

\section{Differences in effects}

Robert et al. (2011) mainly looked into gender differences in the effects of commuting on psychological health and found that although women tend to commute less, they are more influenced by the negative effects of commuting than men. It is argued that this is because women have a greater responsibility for the household. Within their wide variety of tasks besides work, commuting is another competing demand on a woman's time and thus a greater psychological burden.

\subsection{Limitations}

Although the existing literature has produced a rich body of knowledge on subjective wellbeing and transportation, several issues have remained unaddressed in this literature. First, selection effects are often not well-covered. For example, several cross-sectional studies found lower subjective wellbeing among long-distance commuters and among users of public transportation; however, these differences could be due to selection effects, such as unsuccessful unhappy workers settling more often for a job far away. Another point not taken into account is that people have different determined set points (Lykken \& Tellegen, 1996) and personality traits (e.g. Furnham \& Cheng, 1997) that largely affect their mood level. ${ }^{4}$

Another limitation is that earlier research has focused on the average effect of commuting, rather than addressing the heterogeneous relationship between commuting and well-being and specifying what is optimal for whom. Commuting is likely to work out differently for different people and the question is rather how relations differ in subgroups of the general population. For example, where for some people travelling by car can be conducive to their level of affect, for other types of people more active transport modes such as biking or walking have a positive impact on well-being. This is worth knowing, not only for individual commuters, but also for policy makers in the field of transportation.

In our exploratory analysis, we address both selection effects and the heterogeneous relationship between commuting and well-being, where we examine what way of travel feels best for what kind of people.

\section{APPROACH OF THIS STUDY}

\subsection{Concept of happiness}

\footnotetext{
${ }^{4}$ For an exception see Morris and Guerra (2015).
} 
The term 'happiness' has been around since antiquity in Western society, but its meaning has been continuously debated ever since. For this paper, we use the definition of overall happiness developed by Veenhoven (2012:334). Happiness is 'the degree to which an individual judges the overall quality of his/her own life-as-a-whole favorably'. Simply put: how much one likes the life one leads.

Veenhoven distinguishes between 'overall' happiness and the different 'components' of happiness, which function as 'sub-totals' in the overall evaluation of life (Veenhoven 1984, 2009). First, there is the affective component, called 'hedonic level of affect'. This entails how well we feel most of the time. Second, there is the cognitive component, called 'contentment', which is the degree to which we think we have what we want in life. These components of happiness are visually represented in Figure 3.1. The weight of the two sources of happiness is variable, though hedonic level tends to dominate (Veenhoven, 2009). The affective component, hedonic level of affect, is central to this study.

Figure 3.1 about here

\subsection{Research Method: Day Reconstruction Method}

The data is gathered using the Day Reconstruction Method (DRM). Respondents first 'reconstruct' the previous day, listing all the activities that they engaged in and recording with whom they did these activities and where. Next, they rate how well they felt during each of these activities. Thus, DRM is a combination of time-use study and a mood diary. Contrary to traditional survey research, it captures momentary experience rather than global memories and provides a comprehensive view of the day.

DRM is a rather new tool, which was developed by Kahneman et al. (2003). The DRM is an appropriate tool to measure instant happiness over the course of one day by combining features of time-budget measurement and experience sampling. Time-budget studies assess how people spend their time and typically uses diaries (e.g. Juster \& Stafford, 1991).

Experience sampling techniques capture mood of the moment and often use cell phones for that purpose (e.g. Shiffman, Stone \& Hufford, 2008).

\subsection{Data source}

The data was collected through a website called Happiness Indicator, which is available at http://happinessindicator.com. The Dutch variant is named 'GeluksWijzer' (http://www.gelukswijzer.nl). The Happiness Indicator is a combination of a self-help website and a long-term follow up study on happiness. The Happiness Indicator involves an on-line application of the above-mentioned Day Reconstruction Method, in that context called the 'Happiness Diary'.

The Happiness Indicator aims to foster happiness in two ways. In the short term by making people more aware of how happy they are and how much they enjoy their daily activities. Respondents not only get a better view of how they feel most of the time, but can 
also compare with how similar respondents feel. This informs them about chances of getting happier and how. The long-term goal is to get a view on the effects of mayor life choices on happiness, such as having children or early retirement and in particular how such choices work out for different kinds of people. This information should then be used for evidence based happiness education.

The Happiness Indicator is an initiative of health-insurance company VGZ and the Erasmus University Rotterdam. The website has been online in the Netherlands since 2009.

\subsection{Variables}

\section{Demographics}

Respondents were recruited by using client communications of the health-insurance company and free publicity. Interested individuals visited the website and created an account. Next, they enter information about their age, gender, education, income, job specifics, chronic illness, pets, alcohol and tobacco use, height and weight. This 'profile' is used later for comparing with similar respondents.

Commuting and happiness measured using the happiness diary Happiness for this data was measured through the Happiness Diary. The happiness diary is an internet application of the Day Reconstruction Method as described above. In the happiness diary, you can indicate your activities per half hour of the day and then rate your experienced happiness during these activities on a scale from 1-10 as shown in Figures 3.4A and $\mathrm{B}$ and $\mathrm{C}$.

Figures $3.4 \mathrm{~A}$ and $3.4 \mathrm{~B}$ about here

One of the activities is 'in transit'. When that activity takes place before or after work we assume it is 'commuting'. The respondents then indicate with whom they were in transit. Then they indicate with which transport mode they commuted. From the questions, we can thus find if people commute, how long they commute, with what commuting mode, if they commute alone or together and what their mood is during the commute. The hours of their commute show us if this was in or out of rush hour (06:30-09:00 and 16:00-18:30 ANWB, 2015 \& NS, 2015) and if they were commuting to work (morning) or back from work (evening).

The happiness diary can then compare your experienced happiness during different activities with others 'like you' as shown in Figure 3.4C. The average happiness grade for all activities on one day combined represent the average daily mood. The average happiness grade for all activities at home, indicated by the question where this activity found place, represent the average mood at home.

Figure $3.4 \mathrm{C}$ about here

It should be noted that data collected online has some well-known limitations, such as 
problems with the representativeness of the sample and quality of the data. However, given the goal of the 'Happiness Indicator', representativeness is not really a problem. The 'Happiness Indicator' gathers information on particular people, for particular people, in this case mainly on and for well-educated women interested in getting happier than they are. Representativeness' for the general population is therefore not required. What is required is representativeness for the specific goal-group.

In total, the happiness diary provided about 100.000 data points, which allow comparison over time of some 5000 participants.

\subsection{Descriptive Statistics}

\section{Demographics}

The demographic characteristics of the respondents are shown in Table 3.4A. Most of the participants were female ( $82 \%)$, had paid employment (87\%), and were highly educated (62\%). In terms of living-situation $24 \%$ of them lived alone and $38 \%$ had children living at home. On average, the participants worked 4.13 days or 30.7 hours per week. The majority of the participants was active in the non-profit sector.

Obviously, the participants are not representative of Dutch society and the results of this study can therefore not be generalized to the general population in the Netherlands. We do not see this as a major problem, since the goal of this study was to generate information on particular people, for particular people, namely those who would like to improve their happiness through a self-help website. Representativeness for the general population was therefore not required; what was required is exemplification of a specific goal-group.

Table 3.5A about here

\section{Commuting time and mode}

The frequencies for all the commuting aspects are given in Table 2. The participants commuted on average 45 minutes one way, with a standard deviation of 27 minutes. Most participants indicated that they commuted for approximately 30 minutes. The car $(48 \%)$ and bike (27\%) were the most used transport modes, followed by public transport (13\%). The category 'Other/Multimodal' represents commuting using other or multiple transportation modes. The most often mentioned commuting modes that fell into this category were combinations of the active modes of commuting and public transportation (77\%). Over half of the commuting trips (58\%) took place during rush hours, while most respondents (89\%) travelled alone to work.

\section{Table 3.5B about here}

\section{Mood}

The descriptive statistics for the well-being variables are given in Table 3. The average daily mood of respondents at the first time of participation was a 6.7, which is slightly below average affect scores around 7.0 reported in Dutch surveys (see Veenhoven 2015b). During 
$37 \%$ of the activities the mood level was rated 6 or lower. This indicates that the Happiness Indicator website particularly attracts individuals who are less happy than the average citizen is and probably therefore would like to work on their happiness.

Participants feel mostly happier during other times of the day than while commuting. On average, average affect during commuting was rated a 6.5 , which is lower than the 'average mood at home'.

The mean affect level for the main different activities during the working day is shown in Figure 3.5. From the graph, it becomes clear that commuting is, on average, disliked more than other activities, particularly leisure and eating. Likewise, travel for other purposes is evaluated more positively than commuting. At the same time, the average mood level for commuting indicates that most people do not have the most terrible time when commuting.

Table 3.5C about here

Figure 3.5 about here

\section{RESULTS}

The main question of this paper is: What does optimal commuting look like to enhance happiness for whom?' and this question was broken down into the following sub-questions:

1) Does commuting affect happiness? If so, how much?

2) Which aspects of commuting influence happiness most and least?

3) How different are these effects across persons and situations? (cf. section 1)

What answers to these questions do our data allow?

\subsection{Does commuting affect happiness? If so how much?}

The effect of commuting on happiness is captured by the difference in mood during travel and at home. These effects tend to be negative, as can be seen in Table 4.1A, which presents average differences in happiness by aspects of commuting. Likewise, the correlation matrix in table 4.1B links between commuting and happiness.

These statistical relations indicate a causal effect of commuting on happiness. Reversed causation is unlikely to be involved since happiness is measured by with-in person differences. Even if trait-unhappy persons are more likely to commute by public transportation that will not affect this within-person difference in mood during commute and at home. Neither is response bias likely to be involved. If trait happy people tend to have a rosier look on life, that will influence their rating of mood during commuting about as much as their rating of how they feel at home.

Table 4.1 provides also an answer the question of how much commuting affects happiness. The differences in mood during commute and at home vary between +.05 (traveling with someone) to -.70 (travel to between 30 and 60 minutes), that is between $0,5 \%$ and $7 \%$ on this $0-10$ scale. When all commute variables are entered together in a 
regression analysis, an explained variance of 3\% appears (Table 4.1.b). A more sophisticated econometric analysis, reported in Lancee et. al (2017), showed that, on average, mood during commuting is 0.28 points lower compared to average mood during the day.

Table 4.1A about here

\subsection{Which aspects of commuting influence happiness most and least?}

The averages presented in table 4.1a show that public transport goes with the greatest loss in happiness of about half a point (-.50). Commuting by car involves a much smaller loss of happiness and commute by bike the least. The most positive effect was found by a commute with someone for both the comparison of means (+.05), and the correlation matrix (+.09, $p<.05)$.

Split-up by commuting time in table 4.2 hardly changes that picture, but reveals a small positive effect of commuting by bike for about an hour. Surprisingly, we observed little effect of commuting time as such; the loss is more in the mode of transportation than in the duration of transportation. This is illustrated by the size of the happiness dip in public transportation, which is deepest with the shortest commuting time.

Table $4.2 \mathrm{~A}$ and $4.2 \mathrm{~B}$ about here

\subsection{What way of commuting is optimal for whom?}

Average effects of commuting on happiness may veil substantial differences across kinds of people; for instance, a zero correlation may result from a strong positive effect in one-half of a sample and an equally strong positive effect in the other. Since we aim at tailored advice, we split-up in subgroups as far as the allowed. These sub-groups are presented in figure 4.3. As higher educated women are well represented among the participants we could differentiate most in this category.

Figure 4.3 about here

Overall the most optimal commuting mode for highly educated women is most often the bike, and the least optimal commuting mode public transport. However, this is actually the opposite for women living alone without children and working part time.

The most optimal commute is more often a commute with someone, but for several types of highly educated women feel better when commuting alone. Half of highly educated women should commute out of rush hour for an optimal commute, while the other half should commute in rush hour for an optimal commute.

The effects of different commuting modes for each of these subgroups are summarized on table 4.3, in which an ' + ' stands for the commuting aspect that should be used to enhance happiness and a '-' stands for a commuting aspect that should not be used 
when one wants to enhance happiness. When a ' $\downarrow$ ' is given for the commuting time $>0$, this indicates that as commuting time increases, the loss of happiness increases.

Table 4.3 about here

Elsewhere we reported an econometric analysis of these differences (Lancee at al 2017), which revealed striking differences between groups for the different commuting modes. While for men, older, higher-income and higher-educated people the active modes appear to be conducive for mood, this does not hold for the women, young, lower-income and lower-educated; the active modes (walking and biking) do not boost the mood of these latter people. These differences can be explained by differences in lifestyle and location of residence, which need further examination.

Travelling with someone has less effect on the mood of people with children. Apparently when children are the ones on board, e.g., they are being brought to school on a multipurpose commuting trip, travelling with someone is less satisfying than when travelling with partner, colleagues or friends.

\section{DISCUSSION}

\subsection{Main findings}

Analysis of the Happiness Indicator dataset confirms earlier studies that observed a negative effect of commuting on happiness. Beyond that, the within-person comparison shows that the negative effect is causal, that is, not due to selection bias or reversed causality. The analysis has also revealed that the effect of different ways of commuting differ considerably across different kinds of people, even among different kinds of highly educated women.

\subsection{Agenda for further research}

This exploratory study does not allow generalization of the results, not even to the many highly educated women participating in this study and certainly not to the general population in the Netherlands. So next the step is replication of this study using probability samples, be it probability samples of the general population or specific publics, such as highly educated women. Testing of hypothesis and assessing statistical significance will be useful in that context, but was not apt in this exploratory study.

These data used her set limitations. Some information is not available at all, and some information is not represented by a sufficient amount of entries, both limiting specification. Even in some of the specifications that are included in this thesis, several commuting aspects fall away as they are not represented by the minimum of 25 entries. This especially limits the possibilities to combine commuting time and mode, which shows promising results. 
The data did not allow to explore several of the commuting aspects extensively. For one, it was not possible to make a distinction between different means of public transportation. Also, the results show that some types of highly educated women do better travelling out of rush hour, and others in rush hour. This raises the question why travelling in rush hour would enhance happiness for certain kinds of highly educated women. Previous research cannot answer this question and the data does not allow to explore this matter further.

Earlier research has focused on general tendencies and has tried to assess pure effect using regression analysis with many control variables. The wisdom aimed at, is typically a 'best-practice' applicable to all. However, this analysis shows that there are no such general tendencies. The effects of commuting are typically contingent, causing the effects to be different for different kinds of people. There is no one best way for everybody. This is why specification should be more central in future in happiness research.

There is no one-way of commuting that is optimal for everybody. Although public transport is the commuting mode that most commonly causes larges negative effects, it is actually the most optimal commuting mode for highly educated women without children living alone and working part time. For highly educated women it also varies widely if commuting in or out of rush hour, and commuting alone or together leads to the optimal commute. Especially highly educated women with a family income below average, benefit from a commute with others. 


\section{REFERENCES}

Abou-Zeid, M., Witter, R., Bierlaire, M., Kaufmann, V., \& Ben-Akiva, M. (2012). Happiness and travel mode switching: findings from a Swiss public transportation experiment. Transport Policy, 19(1), 93-104.

ANWB. (2015). Dagelijkse drukke trajecten ochtend en avondspits. [online]. Available at: http://www.anwb.nl/verkeer/nederland/verkeersinformatie/dagelijkse-drukke-trajecten. [Accessed 10 Jun. 2015].

Chng, S., White, M., Abraham, C., \& Skippon, S. (2016). Commuting and wellbeing in London: The roles of commute mode and local public transport connectivity. Preventive Medicine, $88(1), 182-188$.

Dolan, P., Peasgood, T., White, M.P. (2006). Review of Research on the Influences on Personal Well-Being and Application to Policy Making. Report for Defra, UK.

Duarte, A., Garcia, C., Giannarakis, G., Limão, S., Polydoropoulou, A., \& Litinas, N. (2010). New approaches in transportation planning: happiness and transport economics. NETNOMICS: Economic Research and Electronic Networking, 11(1), 5-32.

Ettema, D., Friman, M., Gärling, T., Olsson, L.E. \& Fujii, S. (2012). How in-vehicle activities affect work commuters' satisfaction with public transport. Journal of Transport Geography, [http://dx.doi.org/10.1016/j.jtrangeo.2012.02.007].

Ettema, D., Gärling, T., Eriksson, L., Friman, M., Olsson, L.E. \& Fujii, S. (2011). Satisfaction with travel and subjective well-being: Development and test of a measurement tool. Journal of Transportation Research, F, 14, 167-175.

Ettema, D. \& Smajic, I. (2014). Walking, places and wellbeing. The Geographical Journal, 181(2), doi: 10.1111/geoj.12065.

Frey, B.S. \& Stutzer, A. (2002). What Can Economists Learn from Happiness Research? Journal of Economic Literature, Vol. XL, $402-435$.

Frey, B.S. \& Stutzer, A. (2014). Economic Consequences of Mispredicting Utility. Journal of Happiness Studies, 15, 937-956.

Friman, M., Fujii, S., Ettema, D., Gärling, T. \& Olsson, L.E. (2013). Psychometric analysis of the satisfaction with travel scale. Transportation Research, A, 48, 132-145. 
Furnham, A. \& Cheng, H. (1999). Personality as Predictor of Mental Health and Happiness in East and West. Personality and Individual Differences, 27, $395-403$.

Gatersleben, B., Uzzell, D., (2007). Affective appraisals of the daily commute: comparing perceptions of drivers, cyclists, walkers, and users of public transport. Environment and Behavior 39 (3), 416-431.

Gelukswijzer: Gereedschap voor werken aan geluk. Erasmus University Rotterdam, Happiness Economics Research Organization. Available at: https://www.gelukswijzer.nl

The Happiness Indicator: A self-help website and a scientific follow-up study. Erasmus University Rotterdam, Happiness Economics Research Organization.

Available at: http://happinessindicator.com

Juster, F.T. \& Stafford, F.P. (1991). The Allocation of Time: Empirical Findings, Behavioral Models, and Problems of Measurement. Journal of Economic Literature, 29-2, 471-522.

Kahneman, D., Krueger, A.B., Schkade, D.A., Schwarz, N. \& Stone, A.A. (2003). A Survey Method for Characterizing Daily Life Experience: The Day Reconstruction Method (DRM). Mimeo, Princeton University.

Koslowsky, M., Kluger, A.M. \& Reich, M. (1995). Commuting Stress: Causes, Effects, and Methods of Coping. New York: Plenum Press.

Lancee, S., Burger, M. \& Veenhoven, R. (2017). Mood during commute in the Netherlands, Transportation Research Part A, 104C (2017) pp. 195-208.

Layard, R. (2005). Happiness: Lessons of a new science, Penguin, New York, USA.

Lykken, D.T. \& Tellegen, A. (1996). Happiness is a Stochastic Phenomenon, Psychological Science, 7, $186-189$.

Lyubomirsky, S. (2008). The how of happiness: A scientific approach to getting the life that you want. New York: Penguin Press.

Mokhtarian, P. L., \& Salomon, I. (2001). How derived is the demand for travel? Some conceptual and measurement considerations. Transportation Research Part A: Policy and Practice, 35(8), 695-719.

Morris, E. A., \& Guerra, E. (2015). Mood and mode: does how we travel affect how we feel? Transportation, 42(1), 25-43. 
Olsson, L. E., Gärling, T., Ettema, D., Friman, M., \& Fujii, S. (2013). Happiness and satisfaction with work commute. Social Indicators Research, 111(1), 255-263.

ONS. (2014). Commuting and Personal Well-being. Office for National Statistics, London, UK.

Pfaff, S. (2014). Pendelenfernung, Lebenszufriedenheit und Entlohnung: Eine Längsschnittuntersuchung mit den Daten des SOEP von 1998 bis 2009. Zeitschrift für Soziologie, 43, 113-130

Putnam, R.D., 2000. Bowling Alone: The Collapse and Revival of the American Community. Simon \& Schuster, USA.

Roberts, J., Hodgson, R., \& Dolan, P. (2011). "It's driving her mad": Gender differences in the effects of commuting on psychological health. Journal of Health Economics, 30(5), 10641076.

Studer, R. \& Winkelmann, R. (2011). Specification and Estimation of Rating Scale Models: With an Application to the Determinants of Life Satisfaction. SOEP Paper no. 372. Berlin, Germany.

Stutzer, A., \& Frey, B. S. (2008). Stress that doesn't pay: The commuting paradox. Scandinavian Journal of Economics, 110(2), 339-366.

Susilo, Y. O., \& Maat, K. (2007). The influence of built environment to the trends in commuting journeys in the Netherlands. Transportation, 34(5), 589-609.

Van der Meer, P.H. \& Wielers, R. (2013). What Makes Workers Happy? Applied Economics, 45, 357368.

Van Wee, B., Rietveld, P., \& Meurs, H. (2006). Is average daily travel time expenditure constant? In search of explanations for an increase in average travel time. Journal of Transport Geography, 14(2), 109-122.

\section{$\underline{\text { Veenhoven, R. (1984.) Conditions of Happiness, Springer, Dordrecht, Netherlands }}$}

Veenhoven, R. (2009). How do we assess how happy we are? Tenets, implications and tenability of three theories. In: Dutt, A. and Radcliff, B. (eds.), Happiness, Economics and Politics: Towards a multi-disciplinary approach, $1^{\text {st }}$ ed. Cheltenham, UK: Edward Elger Publishers, pp. 45-69.

Veenhoven, R. (2012). Cross-national differences in happiness: Cultural measurement bias or effect of culture? International Journal of Wellbeing, 2(4), 333-353. 
Veenhoven, R. (2015a). Distributional findings on Happiness in Nations. World Database of Happiness, Erasmus University Rotterdam, the Netherlands. [Online]. Available at: http://worlddatabaseofhappiness.eur.nl. [Accessed 21 Jul. 2015].

Veenhoven, R. (2015b). Happiness in Netherlands (NL). World Database of Happiness, Erasmus University Rotterdam, the Netherlands. [Online]. Available at: http://worlddatabaseofhappiness.eur.nl. [Accessed 21 Jul. 2015].

Veenhoven, R. (2015c). Evidence based pursuit of happiness: what should we know, do we know and can we get to know? Erasmus Happiness Economics Research Organization. White paper nr. 1. Erasmus University Rotterdam. [Online]. Available at:

http://www2.eur.nl/fsw/research/veenhoven/Pub2010s/2012j-full.pdf. [Accessed 3. Aug. 2015].

Veenhoven, R. (2016) Happiness, History of the concept. in Wright, J. (ed.) International Encyclopaedia of Social and Behavioural Sciences Elsevier, 2nd edition Vol. 10, pp 521-525, Oxford Elsevier 


\section{TABLES}

Table 3.4A: Demographic characteristics of respondents

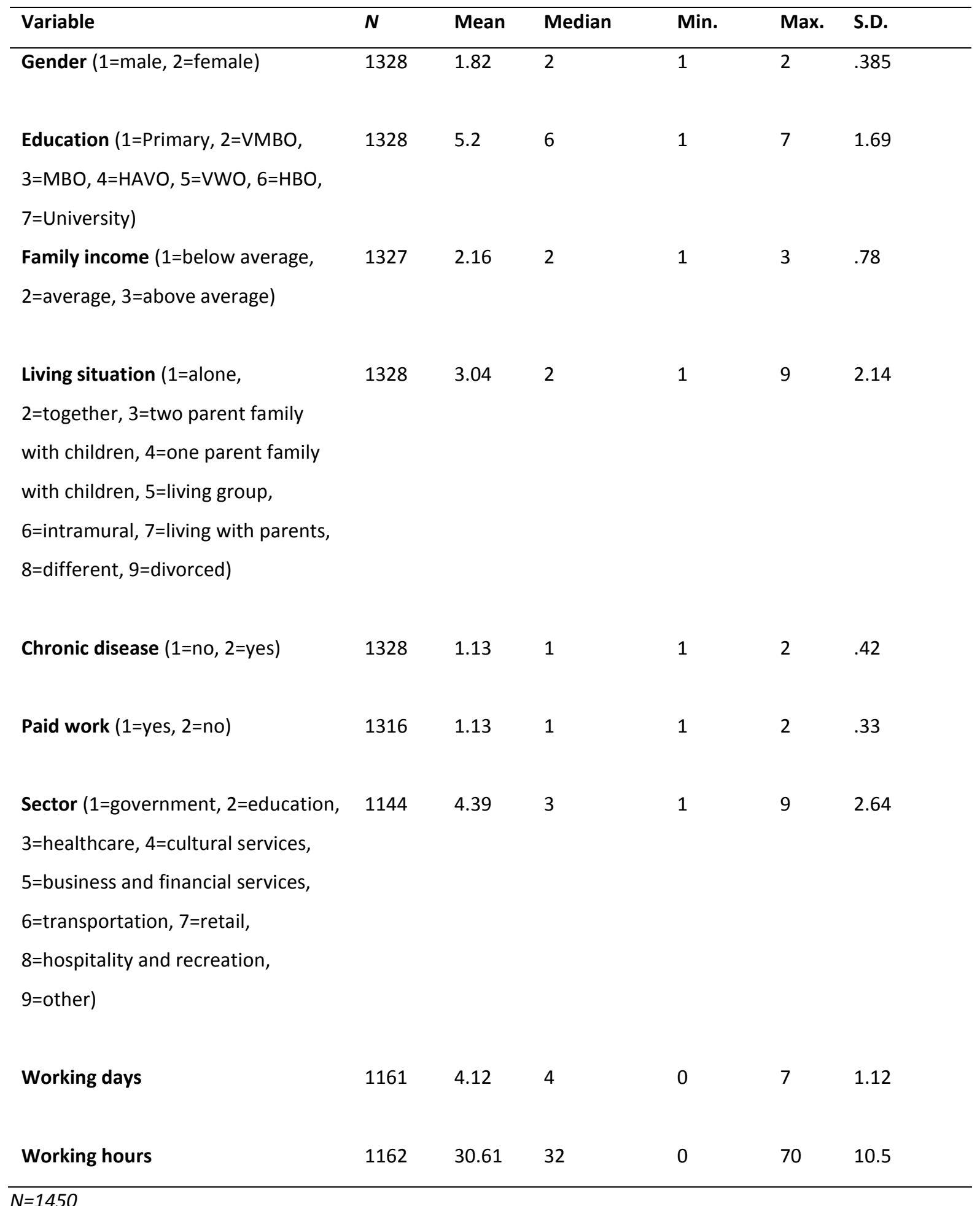


Table 3.4B: Frequencies for the commuting aspects

\begin{tabular}{|c|c|c|c|c|c|c|c|c|c|c|}
\hline Variable & Time & Car & Public & Bike & $\begin{array}{l}\text { Multimodal } \\
\text { with } \\
\text { walking }\end{array}$ & $\begin{array}{l}\text { Multimodal } \\
\text { without } \\
\text { walking }\end{array}$ & $\begin{array}{l}\text { With } \\
\text { someone }\end{array}$ & $\begin{array}{l}\text { In } \\
\text { rush } \\
\text { hour }\end{array}$ & $\begin{array}{l}\text { To } \\
\text { work }\end{array}$ & $\begin{array}{l}\text { Back } \\
\text { from } \\
\text { work }\end{array}$ \\
\hline$N$ & 4354 & 2009 & 582 & 1258 & 238 & 164 & 634 & 3066 & 2495 & 1878 \\
\hline
\end{tabular}


Table 3.5C: Descriptive statistics for happiness variables

\begin{tabular}{lllllll}
\hline Variable & $\mathbf{N}$ & Mean & Median & Min. & Max. & S.d. \\
\hline Average daily mood & 33281 & 7.69 & 7.88 & 1 & 11 & 1.22 \\
Mood during commute & 4345 & 7.45 & 8.00 & 1 & 11 & 1.56 \\
Average mood at home & 33281 & 7.65 & 7.88 & 1 & 11 & 1.30 \\
Difference in mood during & 4345 & -.20 & -.14 & -7.09 & 5.21 & 1.21 \\
commute and at home & & & & & & \\
\hline
\end{tabular}

$N=33,281$ 
Table 3.5A: Commuting and mood: Means on scale 0-10 for the entire population

\begin{tabular}{clcc}
\hline & \multicolumn{2}{c}{$\begin{array}{c}\text { Difference in mood during } \\
\text { commute and at home }\end{array}$} & N data points \\
\hline Time & $<\mathbf{3 0}(\mathbf{0})$ & -.34 & 41 \\
& $\mathbf{3 0}$ & -.70 & 2739 \\
$\mathbf{6 0}$ & -.22 & 1115 \\
$\mathbf{9 0}$ & -.41 & 308 \\
$\mathbf{1 2 0}$ & -.35 & 77 \\
Mode & -.21 & 1995 \\
& Public & -.50 & 577 \\
$\quad$ Bike & -.08 & 1253 \\
$\quad$ Multimodal with walking & -.27 & 238 \\
$\quad$ Multimodal without walking & -.06 & 161 \\
Travel with someone & +.05 & 629 \\
Rush hour & -.21 & 2882 \\
Travel to work & -.29 & 2478 \\
Travel back from work & -.08 & 1867 \\
\hline
\end{tabular}

Data points: $N=33,465$ 
Table 4.2B : Correlation matrix

\begin{tabular}{|c|c|c|c|c|c|c|c|c|c|c|c|c|}
\hline Variable & $M$ & S.D. & 1 & 2 & 3 & 4 & 5 & 6 & 7 & 8 & 9 & 10 \\
\hline $\begin{array}{l}\text { 1. Time (in } \\
\text { min.) }\end{array}$ & 45 & 27 & 1 & & & & & & & & & \\
\hline 2. Car & - & - & -.09 & 1 & & & & & & & & \\
\hline 3. Public & - & - & +.26 & -.03 & 1 & & & & & & & \\
\hline 4. Bike & - & - & -.23 & -.05 & -.03 & 1 & & & & & & \\
\hline $\begin{array}{l}\text { 5. Multimodal } \\
\text { with walking }\end{array}$ & - & - & +.15 & -.02 & -.01 & -.02 & 1 & & & & & \\
\hline $\begin{array}{l}\text { 6. Multimodal } \\
\text { without } \\
\text { walking }\end{array}$ & - & - & +.15 & -.02 & -.01 & -.01 & -.01 & 1 & & & & \\
\hline $\begin{array}{l}\text { 7. Travelling } \\
\text { with someone }\end{array}$ & .02 & .14 & +.06 & +.20 & +.14 & +.23 & +.05 & +.03 & 1 & & & \\
\hline 8. Rush hour & .09 & .29 & -.08 & +.49 & +.27 & +.41 & +.16 & +.14 & +.32 & 1 & & \\
\hline 9. To work & .07 & .26 & -.02 & +.47 & +.24 & +.39 & +.15 & +.14 & +.26 & +.62 & 1 & \\
\hline $\begin{array}{l}\text { 10. Back from } \\
\text { work }\end{array}$ & .06 & .23 & +.02 & +.42 & +.22 & +.31 & +.15 & +.11 & +.23 & +.42 & -.07 & 1 \\
\hline $\begin{array}{l}\text { 11. Difference } \\
\text { mood when } \\
\text { commuting and } \\
\text { at home }\end{array}$ & -.20 & 1.21 & -.02 & -.03 & -.10 & +.06 & -.01 & +.02 & +.09 & -.01 & -.09 & +.09 \\
\hline
\end{tabular}

Notes: $\ln$ bold $=p<0.05, N=33465$ 
Table 4.1c: Explained variance of the different regression analyses

\begin{tabular}{lllllllll}
\hline Variable & \multicolumn{2}{l}{$\begin{array}{l}\text { Average daily } \\
\text { mood }\end{array}$} & \multicolumn{2}{l}{$\begin{array}{l}\text { Mood during } \\
\text { commute }\end{array}$} & Mood at home & \multicolumn{2}{l}{$\begin{array}{l}\text { Difference in mood during } \\
\text { commute and at home }\end{array}$} \\
\hline \multirow{2}{*}{$\mathbf{R}^{2}$} & $\underline{M 1}$ & $\underline{M 2}$ & $\underline{M 1}$ & $\underline{M 2}$ & $\underline{M 1}$ & $\underline{M 2}$ & $\underline{M 1}$ & $\underline{M 2}$ \\
Adjusted $\mathbf{R}^{2}$ & .04 & .05 & .02 & .05 & .04 & .05 & .01 & .03 \\
\hline
\end{tabular}


Table 4.2: mean loss or gain of happiness combining commuting time and mode for the entire population

\begin{tabular}{|c|c|c|c|c|c|c|}
\hline & \multicolumn{6}{|c|}{ Commuting time } \\
\hline & $\underline{30(\min )}$ & $\underline{N}$ & $\underline{60(\min )}$ & $\underline{N}$ & $90-120(\min )$ & $\underline{n}$ \\
\hline \multicolumn{7}{|l|}{ Commuting mode } \\
\hline Car & -.19 & 1348 & -.22 & 473 & -.34 & 141 \\
\hline Public transport & -.66 & 141 & -.37 & 274 & -.59 & 153 \\
\hline Bike & -.11 & 1040 & +.04 & 183 & +.06 & 17 \\
\hline Multimodal with walking & -.22 & 78 & -.38 & 93 & -.13 & 62 \\
\hline $\begin{array}{l}\text { Multimodal without } \\
\text { walking }\end{array}$ & -.14 & 35 & -.02 & 81 & -.01 & 39 \\
\hline
\end{tabular}




\begin{tabular}{|c|c|c|c|c|c|c|c|c|c|c|c|c|c|c|c|c|c|c|c|c|c|}
\hline \multirow{3}{*}{ 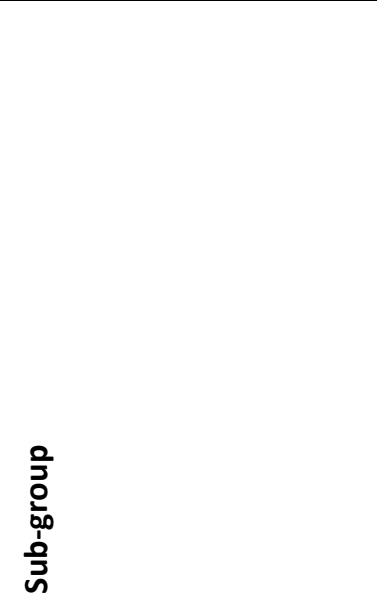 } & \multicolumn{4}{|c|}{$\varangle-$} & \multicolumn{17}{|c|}{ Highly educated women only } \\
\hline & $\sum^{\frac{\sigma}{\nu}}$ & $\begin{array}{l}\text { d } \\
\text { हे } \\
\text { ’ }\end{array}$ & 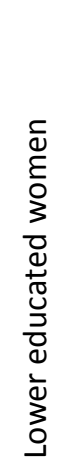 & 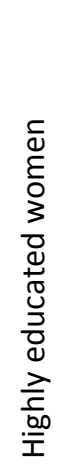 & 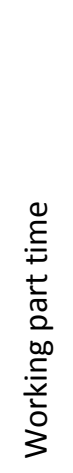 & 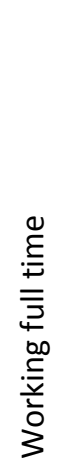 & 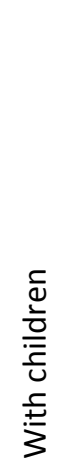 & 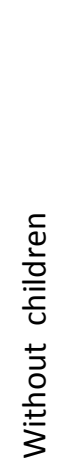 & 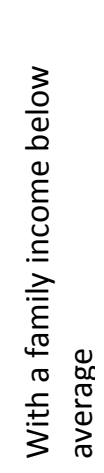 & 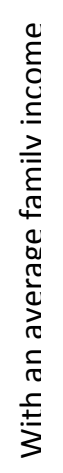 & 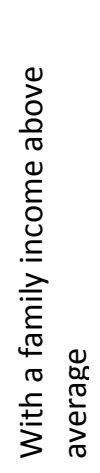 & 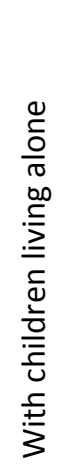 & 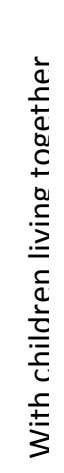 & 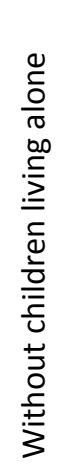 & 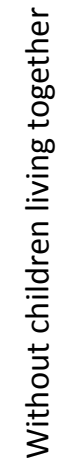 & 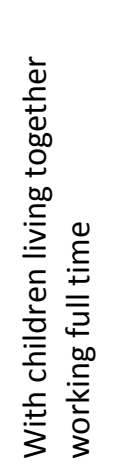 & 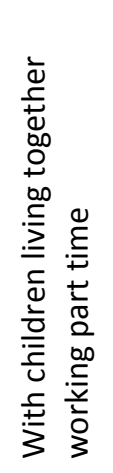 & 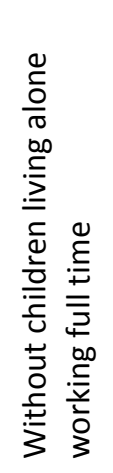 & 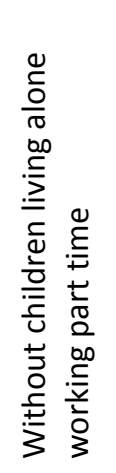 & 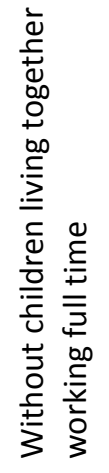 & 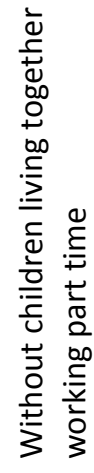 \\
\hline & i & $\dot{m}$ & $\dot{\nabla}$ & ம் & $\dot{\varphi}$ & $r^{\circ}$ & $\infty$ & $\dot{\sigma}$ & 위 & $\ddot{\sigma}$ & $\underset{\sim}{\sim}$ & $\stackrel{\dot{r}}{\rightarrow}$ & $\stackrel{\dot{I}}{\sim}$ & ம் & $\dot{\varphi}$ & $\dot{\vec{r}}$ & $\stackrel{\infty}{\sim}$ & $\stackrel{\text { ㇒े }}{\circ}$ & $\dot{\sim}$ & வ் & $\stackrel{N}{N}$ \\
\hline $\mathbf{N}$ & $? ?$ & ?? & & & & & & & & & & & & & & & & & & & \\
\hline \multicolumn{22}{|l|}{ Time minutes, one way } \\
\hline$>0$ & $\downarrow$ & $\downarrow$ & $\downarrow$ & $\downarrow$ & $\downarrow$ & & $\downarrow$ & $\downarrow$ & $\downarrow$ & $\downarrow$ & $\downarrow$ & $\downarrow$ & $\downarrow$ & $\downarrow$ & $\downarrow$ & $\downarrow$ & $\downarrow$ & $\downarrow$ & & $\downarrow$ & $\downarrow$ \\
\hline $60-90$ & & & & & & & + & & + & & & & + & + & & + & & & & & \\
\hline \multicolumn{22}{|l|}{ Mode } \\
\hline Car & & & & & & & & & & & & & - & & & - & & + & & & \\
\hline Public & - & - & - & - & - & & - & - & - & & - & - & & - & & & & - & + & - & \\
\hline Bike & + & + & & + & + & + & + & + & & + & + & + & + & & + & + & + & + & - & + & + \\
\hline Multimodal with walking & & & + & & & - & & & & - & & & & & - & & & & & & - \\
\hline $\begin{array}{l}\text { Multimodal without } \\
\text { walking }\end{array}$ & + & & & & & & & & + & - & & & & + & - & & & & & & - \\
\hline \multicolumn{22}{|l|}{ With whom } \\
\hline With someone & + & + & + & + & + & + & + & & + & + & + & & + & + & & + & + & + & & & \\
\hline Alone & & & & & & & & & & & & + & & & + & & & & & & + \\
\hline When & & & & & & & & & & & & & & & & & & & & & \\
\hline
\end{tabular}


In rush hour

Out of rush hour
$+$
$+$ 
Figure 3.1: Components of happiness

\section{Overall happiness}

life satisfaction

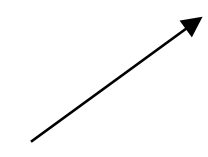

Hedonic level of affect

How well one feels most of the time

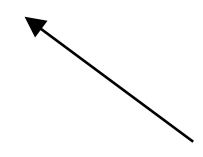

Contentment

Getting what one wants from life 
Figure 3.4A: Example of a Happiness Diary

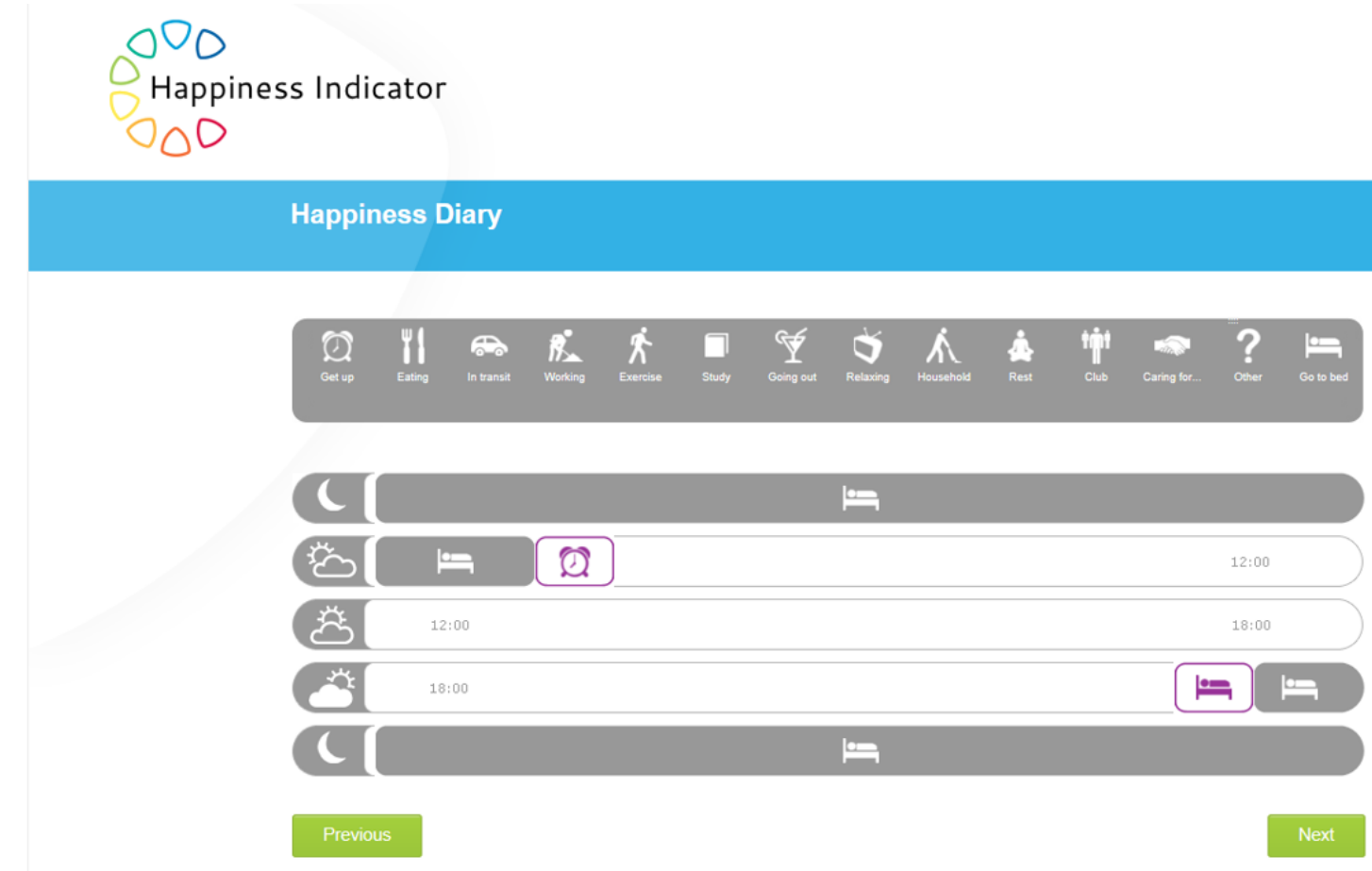


Figure 3.4B: Rating of happiness during daily activities

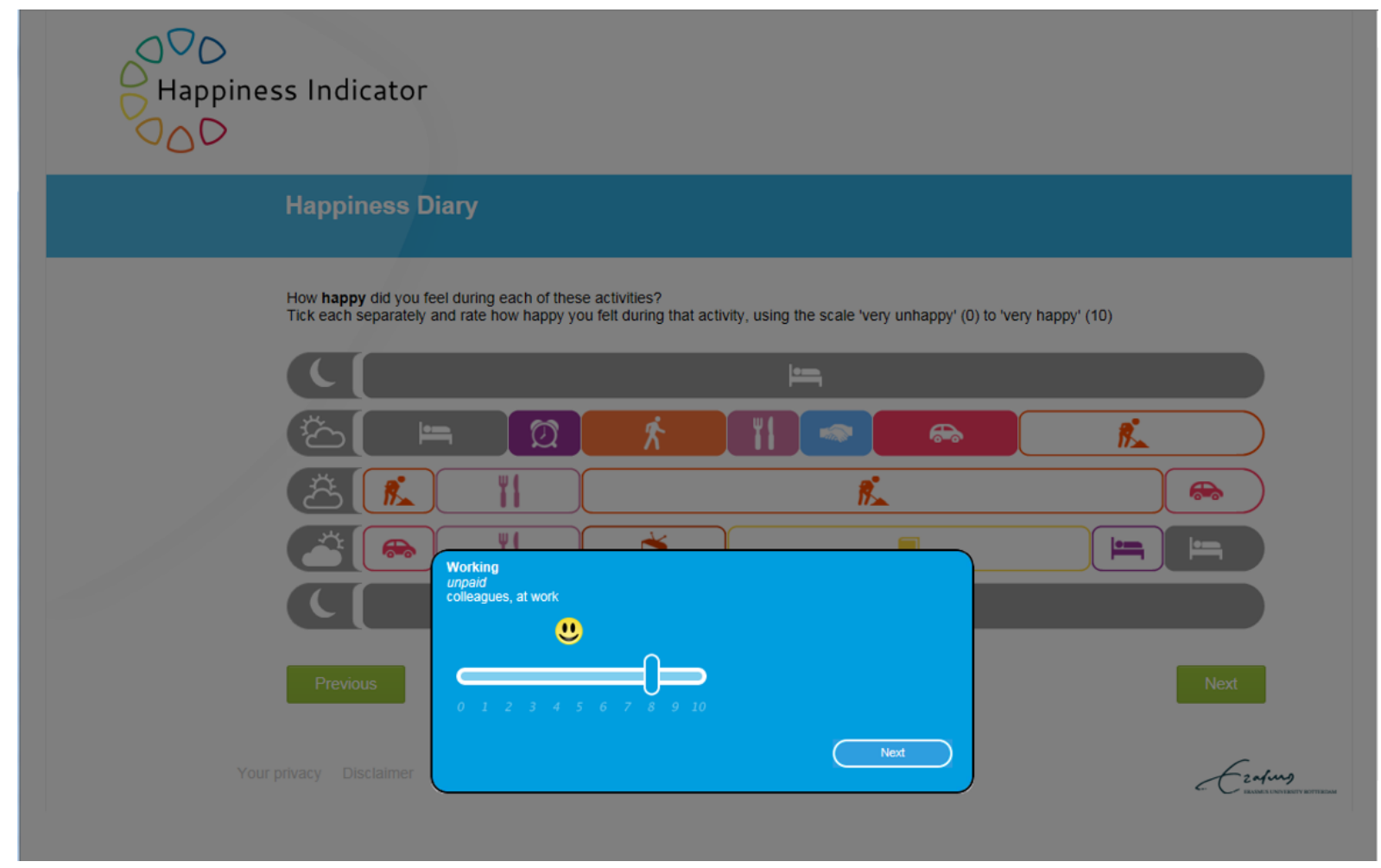


Figure 3.4C:

Comparison of an individual's mood during activities with the average of similar people

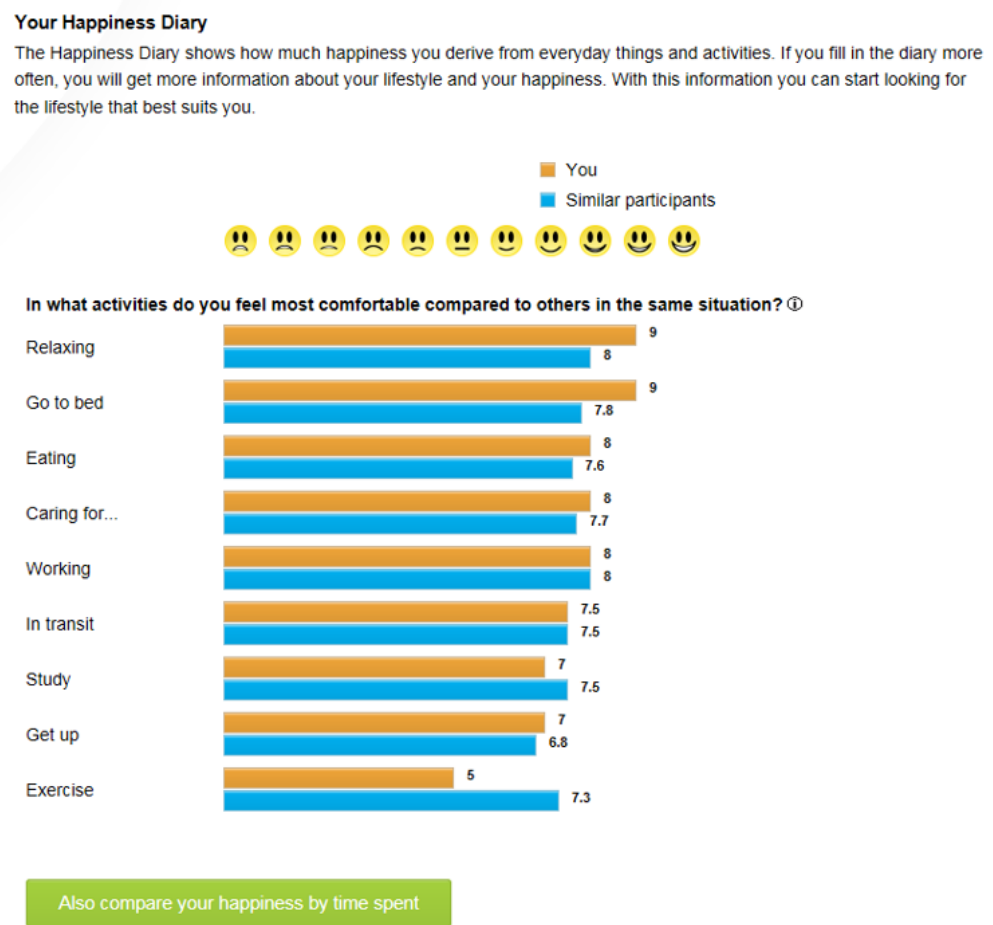


Figure 3.5: Average affect levels during main activities of the working day

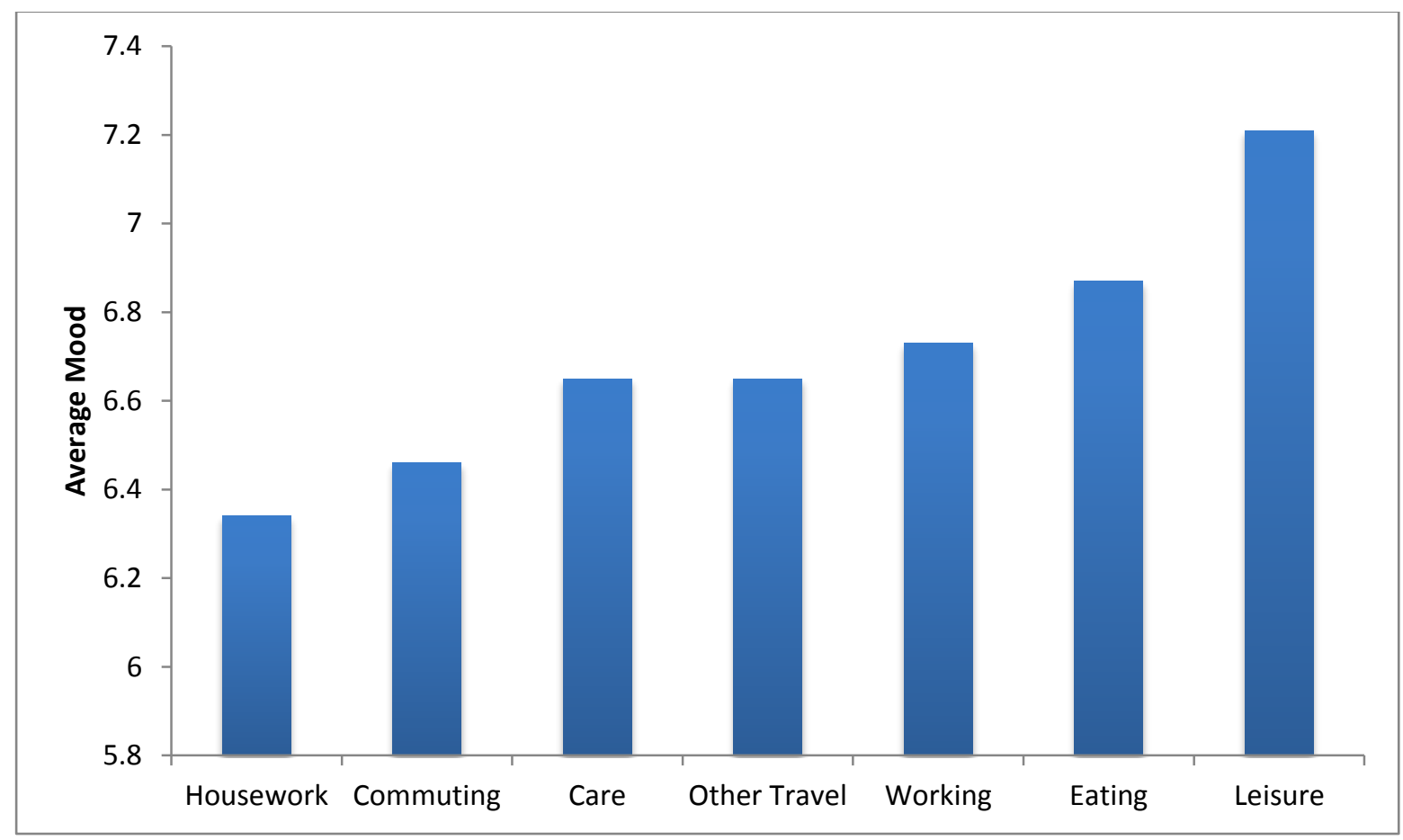


Figure 4.3: Overview of sub-groups

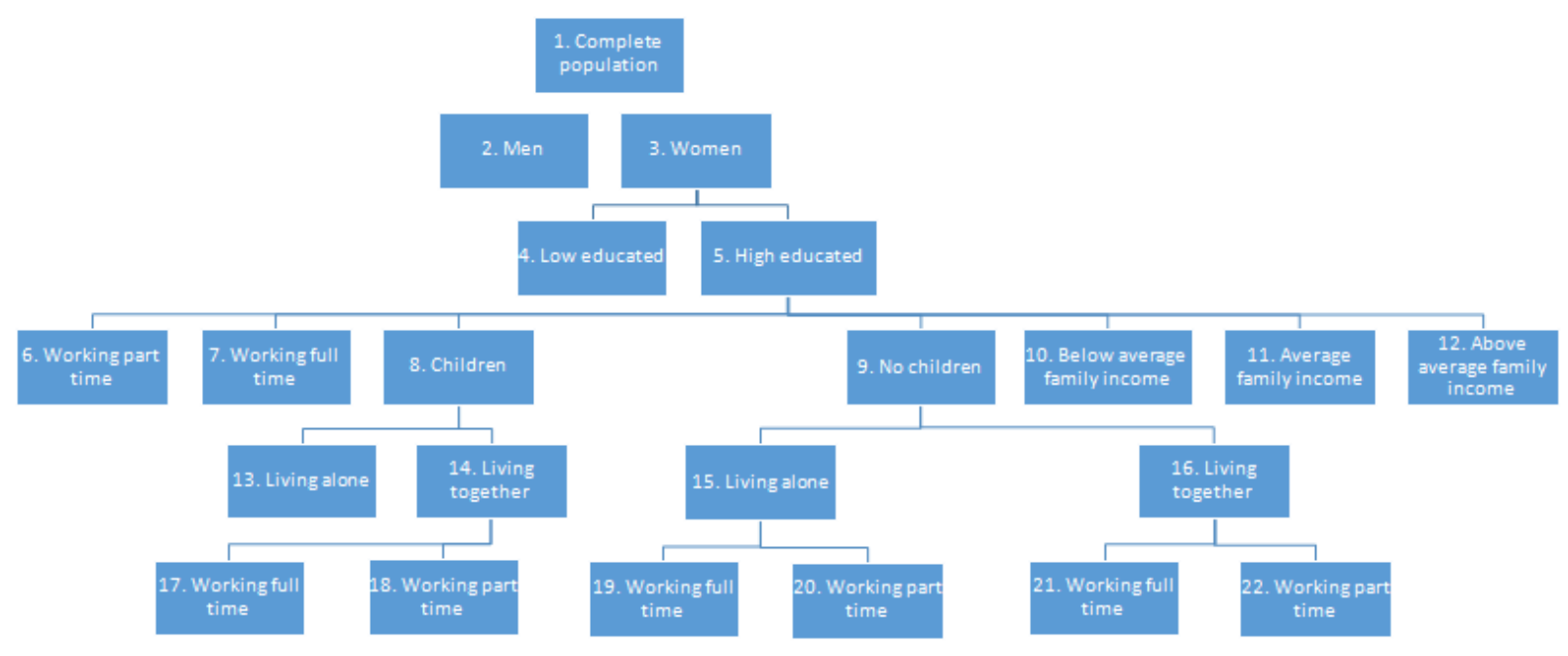

